\title{
Study of Random Blood Sugar and Magnesium in Psoriasis Individuals of Bundelkhand Region: A Case Control Analysis
}

\author{
Qurie Madhura' ${ }^{1}$, Doddigarla Zephy*1 and Lingidi Jhansi Lakshmi ${ }^{2}$ \\ ${ }^{1}$ Environmental Science, Andhra University, Visakhapatnam \\ ${ }^{2}$ Department of Biochemistry, Hi-Tech Medical College \& Hospital, Rourkela, Odisha \\ ${ }^{3}$ Department of Biochemistry, MLB Medical College, India \\ *Corresponding author: Doddigarla Zephy, Department of Biochemistry, Hi-Tech Medical College \& Hospital, Rourkela, Odisha
}

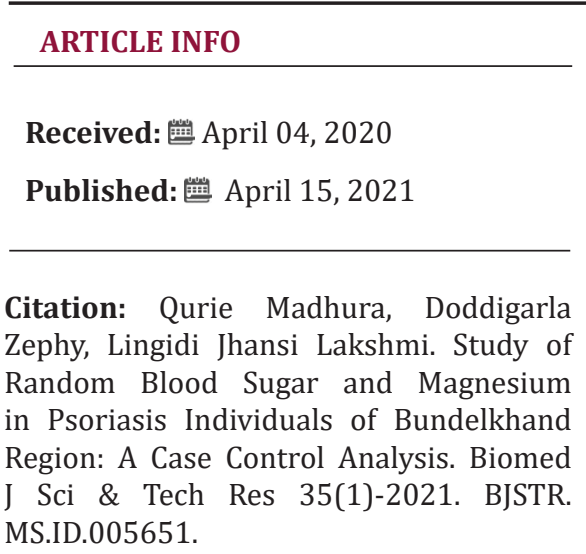

\begin{abstract}
Introduction: There has been little study on psoriasis individuals in the initial period of the disease and during the course of disease on blood glucose and magnesium levels. As a damaging factor of these variables have not been considered in existing studies, therefore, we undertook to study levels of Random Blood Glucose (RBS) and magnesium levels of psoriasis disease patients during then comparing the results with a sex, age matched control group.
\end{abstract}

Materials \& Methods: Age \& sex matched fifty human non-psoriatic individuals were taken into healthy control group. Fifty psoriasis subjects, on treatment were included in Psoriasis group. The diagnosis of psoriasis was made according to the norms laid by American Academy of Dermatology. The diagnosis of psoriasis group subjects was done by the consultants of skin department of MLBMC.

Results: Comparison of age parameter between psoriasis and control group subjects showed insignificant difference, whereas parameters of RBS and magnesium mean levels showed a significant difference. Though the RBS mean level of healthy control was on the higher side but when compared between the two groups, we observed approximately 30 percent high in psoriasis individuals than the control.

Conclusion: With magnesium depletion existed hyperglycemia in psoriasis subjects therefore, it may be advisable to periodically monitor magnesium concentrations in the same. Moreover, further research is imminent to understand the deeper insights into the association of magnesium with psoriasis.

\section{Introduction}

Psoriasis is an auto-immune skin disorder, exhibited by silvery scales and associated sometimes with itching and pain [1]. There are a few explanations for the connection between psoriasis and hyperglycemia (increased blood glucose level), but lately research reports both conditions share certain risk factors in common [2,3]. Tumor necrosis factor is associated with serine phosphorylation of insulin receptor substrate with regards to insulin resistance [4]. In a study on psoriasis patients has been revealed that TNF blockers improved insulin sensitivity and lowered blood glucose levels in the same [5]. In relation to weight, both the conditions have been reported to lower blood glucose and also blood pressure respectively after a weight loss of 5 to10 percent from their base body weight [6]. The other explanation that runs in common for both the diseases is genetic involvement. A study found that variation at IL12B, IL23R and IL23A is associated with psoriasis and hyperglycemia $[7,8]$. Last but not the least, both the conditions are chronic inflammatory disorders and have auto-immune hypothesis in their etiological background [1,9]. Keeping in view of the above cited literature intricately relates the association 
of psoriasis with hyperglycemia, however a future research into the insight of controlling psoriasis will help lower the chances of getting hyperglycemia. The first research according to internet on the association of psoriasis with hyperglycemia dated as far as back to 1966, where a report on fasting blood glucose levels in 94 patients for psoriasis were found to be similar to those in a matched group of controls without psoriasis [10].

The very next year, a retrospective study on the same reported that altered blood sugar levels were seen in $29 \%$ of psoriasis group patients when compared to their control group subjects provide obesity and family history for hyperglycemia were taken as common for both the group subjects [11]. Later on, several cross-sectional have demonstrated increased occurrence of hyperglycemia in patients suffering with psoriasis [12,13]. A similar type of study demonstrated that increased prevalence of hyperglycemia in psoriatic patients was independent of risk factors like obesity and altered lipid profile [14]. Another such study has observed a significant association between psoriasis and insulin resistance [15]. Curiosity in the role of magnesium in medical research has been rising in recent decade. Magnesium seems to be essential for humans and various metabolic processes are dependent on its normal concentrations. Magnesium deficiency has been implicated in various diseases including diabetes, anaemia, depression, ageing, low sexual potency and heart disease $[16,17]$. The interesting risk factor is magnesium bioavailability in hyperglycemic individuals. Considering the hypothesis of association of psoriasis with hyperglycemia, literature demonstrates that during hyperglycemia there is loss of magnesium [18-20]. The causes that could relate to this loss are frequent urination, insulin resistance, absorption, and deficient intake [21,22]. The role of magnesium in psoriasis individuals has not yet been well clarified in psoriasis, especially in this specific part of India (Bundelkhand region). Moreover, there has been little study on psoriasis individuals in the initial period of the disease and during the course of disease on blood glucose and magnesium levels as a damaging factor have not been considered in existing studies, therefore, we undertook to study levels of blood glucose and magnesium levels of psoriasis disease patients during then comparing the results with a sex, age matched control group.

\section{Materials and Methods}

The study was conducted in the Department of Biochemistry, Maharani Laxmi Bai Medical college (MLBMC), Jhansi. Age \& sex matched fifty human non-psoriatic individuals were taken into healthy control group. Fifty psoriasis subjects, on treatment were included in Psoriasis group. The diagnosis of psoriasis was made according to the norms laid by American Academy of Dermatology. The diagnosis of psoriasis group subjects was done by the consultants of skin department of MLBMC. Exclusion criteria were severe psoriatic individuals, less than five years of known duration of psoriasis, and with known complications. Inclusion criteria for healthy controls were non-psoriatic, not taking supplementations, and having no other complications. Fasting venous blood $(5 \mathrm{ml})$ were drawn into fluoride and plane vials, after informed written consent from all the study group subjects with a disposable syringe \& needle, under all aseptic conditions. Serum was separated by centrifuging the blood at $3000 \mathrm{rpm}$ for 20 minutes. Samples were stored in aliquots at -20 o C until assayed. Plasma glucose was estimated by using the method Glucose Oxidase and Peroxidase (DPEC - GOD/POD) purchased from Avantor laboratories. Serum Magnesium (Mg) was estimated by Calmagite Method according to the instructions given in the manual kit.

\section{Precautions While Estimation of $\mathbf{M g}$}

Glassware was immersed in $1.6 \mathrm{~mol} / \mathrm{L}$ nitric acid for $24 \mathrm{H}$, then rinsed four times with water, and micropipette tips prior to use were rinsed in $0.8 \mathrm{~mol} / \mathrm{L}$ nitric acid and then rinsed for three times in water and were allowed to dry on a absorbent paper shown not to contaminate with minerals.

\section{Statistical Analysis}

Microsoft excel was used to perform statistical analysis. Unpaired ' $t$ ' test was performed to compare the means of variables between two groups. Percentages were also calculated. $\mathrm{P}<0.05$ was considered significant.

\section{Results}

\section{Biochemical Parameters in Psoriasis and Healthy Control}

Age, Random Blood Sugar (RBS), and serum magnesium mean levels are shown in Figures 1-3. Comparison of age parameter between psoriasis and control group subjects showed insignificant difference (Figure 1), whereas parameters of RBS ( $t=5.8347$; $\mathrm{d}=98$; $\mathrm{P}<0.05)$ and magnesium mean levels $(\mathrm{t}=7.98 ; \mathrm{df}=98 ; \mathrm{P}<0.05)$ showed a significant difference (Figures $2 \& 3$ ). Though the RBS mean level of healthy control was on the higher side but when compared between the two groups, we observed approximately 30 percent high in psoriasis individuals than the control. In case of serum magnesium we observed almost fifty percent lower magnesium level in psoriasis subjects than in control subjects. We measured the percentages increase due to the fact that we included age and sex matched individuals in both the groups. 


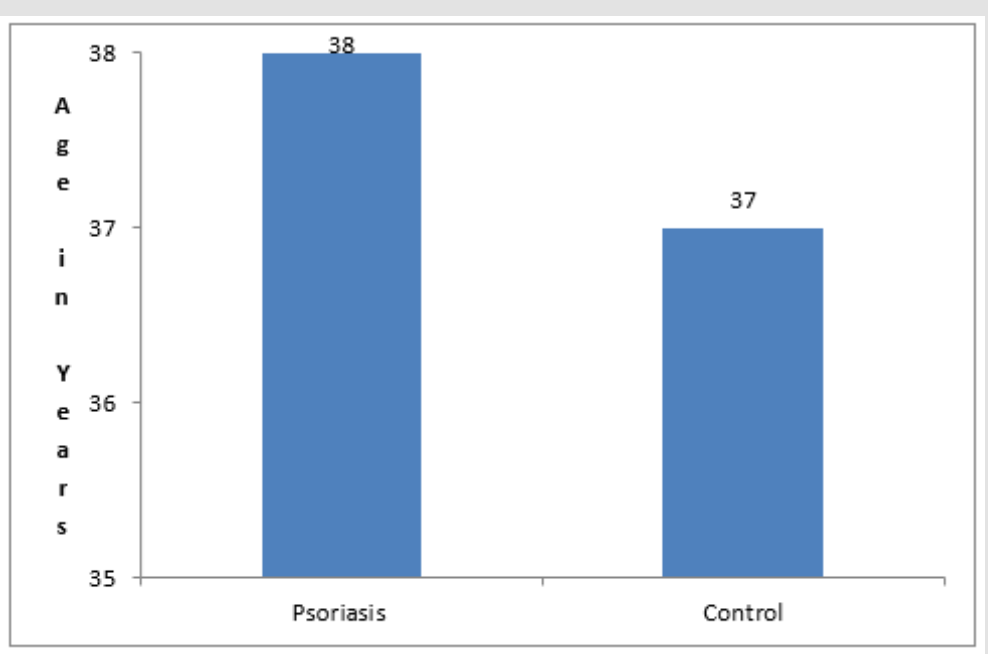

Figure 1: Mean values of Age in years in psoriasis and control group subjects.

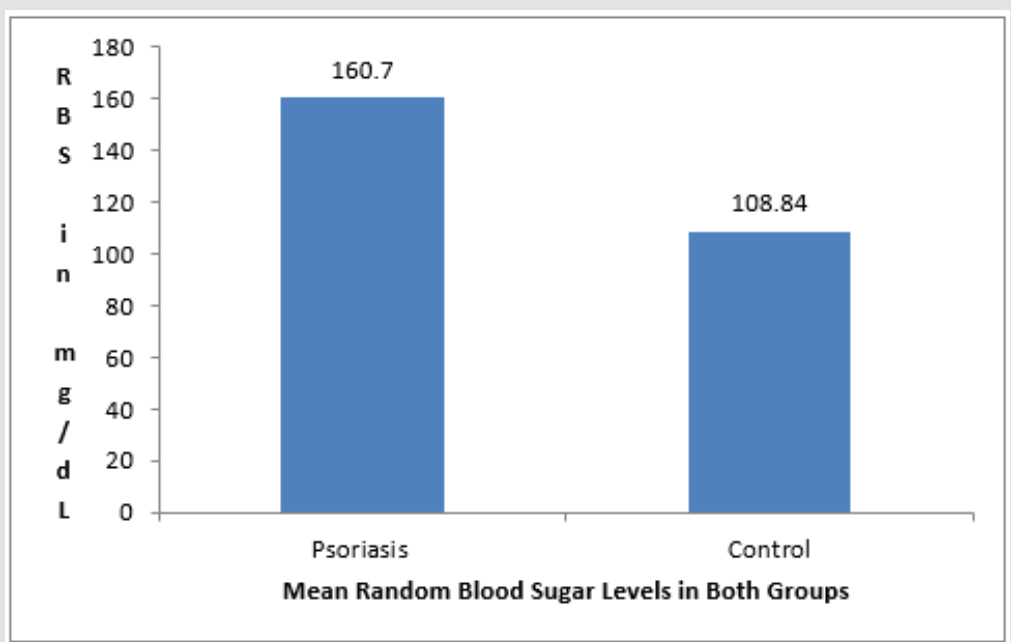

Figure 2: Mean values of Random Blood Sugar in psoriasis and control group subjects.

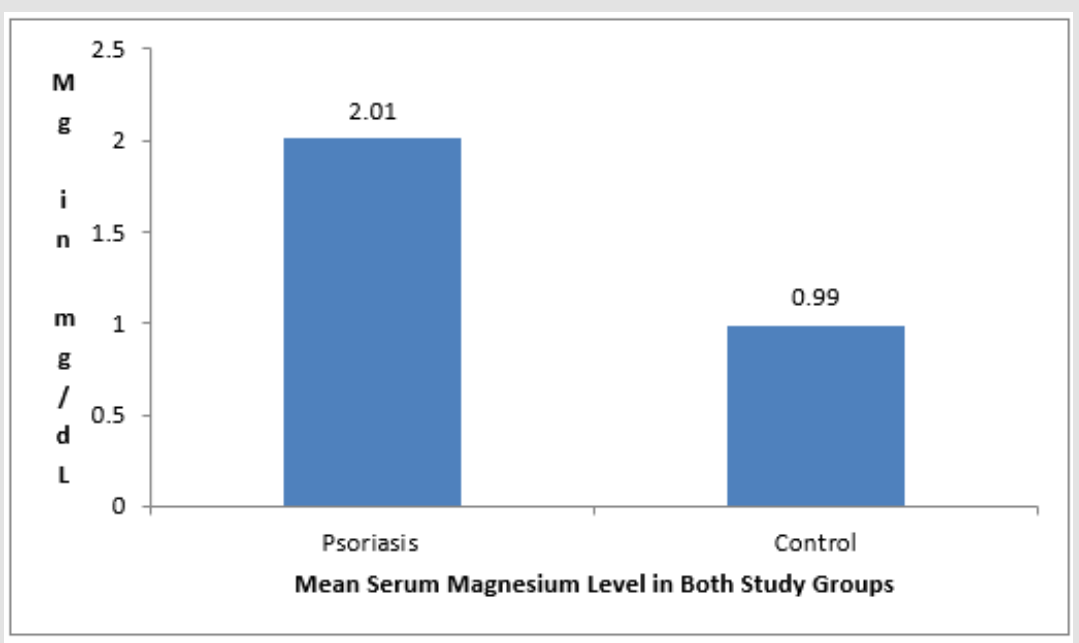

Figure 3: Mean values of serum magnesium in psoriasis and control group subjects. 


\section{Discussion}

Studies demonstrated $[16,17]$ on the role of serum minerals in diseases and that the relationship between nutrition and disease was suspected dated back to $16^{\text {th }}$ century and lately in the last twenty years, numerous studies have found alterations in magnesium status of patients with various diseases. In some studies [23-25], deficiency of magnesium has been correlated with the presence of diseases and also with their respective disease complications. Physiologically, magnesium plays a vital role as cofactor for some enzymes of the glycolytic pathway [26]. It has been also shown that magnesium is necessary for enhancing insulin action on the cell surface of insulin dependent tissues [27]. In another study, it has been shown that deficiency of magnesium mineral has impaired tyrosine kinase activity, thus blunting glucose transport into the cells [28]. Tyrosine kinase is the enzyme that phosphorylates tyrosine residues present on the insulin receptor substrates [26]. All unabsorbed magnesium as well as that in biliary excretion and intestinal secretion is excreted through feces [26]. A fraction of absorbed magnesium is excreted by the kidneys through urine [26].

In the present study, lower serum level of magnesium was observed in the psoriatic subjects compared to the non-psoriatics (controls) subject population of the study. There is little information available on the internet with regards to magnesium concentration in psoriasis individuals across the globe. Therefore, the mechanism responsible for low magnesium level in patients with psoriasis is not completely known. Confining to the present study results, we infer that psoriasis is a disease in which there is excessive skin cells production. With respect to that, glucose is the main source of energy to the cells, and more importantly, magnesium is very much needed for the oxidation of glucose to provide energy. Thus, we imply deficiency of magnesium is due to the fact of more consumption from the magnesium stores in the body and deficient replenish of magnesium stores. The other reason for low magnesium levels is that re-absorption of magnesium takes place in the renal tubules, and for this insulin sensitivity is essential. Lack of sufficient magnesium affects the insulin action and also insulin sensitivity, thus the re-absorption in the renal tubules is impaired. However, reports do exist on the treatment of psoriatic individuals with relation to administration of magnesium salts to the same [29-32]. In addition, these reports [29-32] have also found that administering magnesium salts have attenuated the disease symptoms to some extent. The clinical significance and evaluation at a cellular and molecular level of magnesium in regard to psoriasis remains unaddressed.

In the present study, we also observed hyperglycemia in individuals with psoriasis when compared to non-psoriatic control subjects. Our study results are in support with other study results [10-15]. A study on south Indian psoriasis also revealed hyperglycemia along with The possible reason that can attribute to the hyperglycemia is that studies have demonstrated insulin regulates the intracellular magnesium concentration by stimulating the cell membrane pumps and increases free magnesium entry into the cells [33], so the low serum magnesium levels seen in the present study psoriasis individuals may be a consequence of insulin resistance. Therefore we infer that due to insulin resistance there has been hyperglycemia in the psoriasis subjects in the study.

\section{Conclusion}

In conclusion, we have demonstrated that lower magnesium levels in psoriasis individuals in the Bundelkhand region. With magnesium depletion existed hyperglycemia in psoriasis subjects therefore, it may be advisable to periodically monitor magnesium concentrations in the same. Moreover, further research is imminent to understand the deeper insights into the association of magnesium with psoriasis.

\section{Conflict of Interest}

None declared.

\section{References}

1. Azfar RS, Gelfand JM (2008) Psoriasis and metabolic disease: epidemiology and pathophysiology. Current opinion in rheumatology 20(4): 416-422.

2. Coto-Segura P, Eiris-Salvado N, González-Lara L, Queiro-Silva R, Martinez-Camblor P, et al. (2013) Psoriasis, psoriatic arthritis and type 2 diabetes mellitus: a systematic review and meta-analysis. British Journal of Dermatology 169(4): 783-793.

3. Peserico A, Vena GA, Tiberti S, Chimenti S, Peris K (2009) Risk factors of hypertension, diabetes and obesity in Italian psoriasis patients: a survey on socio-demographic characteristics, smoking habits and alcohol consumption. Eur J Dermatol 19(3): 252-256.

4. Hotamisligil GS, Shargill NS, Spiegelman BM (1993) Adipose expression of tumor necrosis factor-alpha: direct role in obesity-linked insulin resistance. Science 259(5091): 87-91.

5. Barra L, Pope JE, Payne M (2009) Real-world anti-tumor necrosis factor treatment in rheumatoid arthritis, psoriatic arthritis, and ankylosing spondylitis: cost-effectiveness based on number needed to treat to improve health assessment questionnaire. The Journal of rheumatology 36(7): 1421-1428.

6. Tuomilehto J, Lindström J, Eriksson JG, Valle TT, Hämäläinen H, et al. (2001) Prevention of type 2 diabetes mellitus by changes in lifestyle among subjects with impaired glucose tolerance. New England Journal of Medicine 344(18): 1343-1350.

7. Eirís N, González-Lara L, Santos-Juanes J, Queiro R, Coto E, et al. (2014) Genetic variation at IL12B, IL23R and IL23A is associated with psoriasis severity, psoriatic arthritis and type 2 diabetes mellitus. Journal of dermatological science 75(3): 167-172.

8. Oka A, Mabuchi T, Ikeda S, Terui T, Haida Y, et al. (2013) IL12B and IL23R gene SNPs in Japanese psoriasis. Immunogenetics 65(11): 823-828.

9. Johnson RJ, Perez-Pozo SE, Sautin YY, Manitius J, Sanchez-Lozada LG, et al. (2009) Hypothesis: could excessive fructose intake and uric acid cause type 2 diabetes?. Endocrine reviews 30(1): 96-116.

10. Brownstein MH (1966) Psoriasis and diabetes mellitus. Archives of dermatology 93(6): 654-655.

11. Lynch PJ (1967) Psoriasis and blood sugar levels. Archives of dermatology 95(3): 255-258. 
12. Cohen AD, Gilutz H, Henkin Y, Zahger D, Shapiro J, et al. (2007) Psoriasis and the metabolic syndrome. Acta dermato-venereologica 87(6): 506509.

13. Sommer DM, Jenisch S, Suchan M, Christophers E, Weichenthal M (2007) Increased prevalence of the metabolic syndrome in patients with moderate to severe psoriasis. Archives of dermatological research 298(7): 321-328.

14. Neimann AL, Shin DB, Wang X, Margolis DJ, Troxel AB, et al. (2006) Prevalence of cardiovascular risk factors in patients with psoriasis. Journal of the American Academy of Dermatology 55(5): 829-835.

15. Boehncke S, Thaci D, Beschmann H, Ludwig RJ, Ackermann H, et al. (2007) Psoriasis patients show signs of insulin resistance. British Journal of Dermatology 157(6): 1249-1251.

16. Kolte D, Vijayaraghavan K, Khera S, Sica DA, Frishman WH (2014) Role of magnesium in cardiovascular diseases. Cardiology in review 22(4) 182-192.

17. Rayssiguier Y (1986) Magnesium, lipids and vascular diseases Experimental evidence in animal models. Magnesium 5(3-4): 182-190.

18. Matz R (1993) Magnesium: deficiencies and therapeutic uses. Hospital practice 28(3): 79-92.

19. Musso CG (2009) Magnesium metabolism in health and disease. International urology and nephrology 41(2): 357-362.

20. Sowers JR, Standley PR, Ram JL, Jacober S, Simpson L, et al. (1993) Hyperinsulinemia, insulin resistance, and hyperglycemia: contributing factors in the pathogenesis of hypertension and atherosclerosis. American journal of hypertension 6(7_Pt_2): 260S-270S.

21. Barbagallo M, Belvedere M, Dominguez LJ (2009) Magnesium homeostasis and aging. Magnesium Research 22(4): 235-246.

22. Paolisso G, Barbagallo M (1997) Hypertension, diabetes mellitus, and insulin resistance: the role of intracellular magnesium. American journal of hypertension 10(3): 346-355

ISSN: 2574-1241

DOI: 10.26717/BJSTR.2021.35.005651

Doddigarla Zephy. Biomed J Sci \& Tech Res

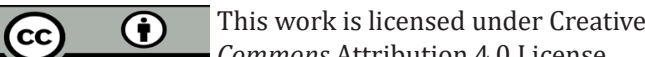

Submission Link: https://biomedres.us/submit-manuscript.php
23. Chakraborti S, Chakraborti T, Mandal M, Mandal A, Das S, et al. (2002) Protective role of magnesium in cardiovascular diseases: a review. Molecular and cellular biochemistry 238(1-2): 163-179.

24. Sullivan JF, Blotcky AJ, Jetton MM, Hahn HK, Burch RE (1979) Serum levels of selenium, calcium, copper magnesium, manganese and zinc in various human diseases. The Journal of nutrition 109(8): 1432-1437.

25. Long S, Romani AM (2014) Role of cellular magnesium in human diseases. Austin journal of nutrition and food sciences 2(10): 1051.

26. Vasudevan (2010) Text book of medical biochemistry.

27. Barbagallo M, Dominguez LJ, Galioto A, Ferlisi A, Cani C, et al. (2003) Role of magnesium in insulin action, diabetes and cardio-metabolic syndrome X. Molecular aspects of medicine 24(1-3): 39-52.

28. Suarez A, Pulido N, Casla A, Casanova B, Arrieta FJ, et al. (1995) Impaired tyrosine-kinase activity of muscle insulin receptors from hypomagnesaemic rats. Diabetologia 38(11): 1262-1270.

29. Biener HF, Biener Hans F (1990) Salt mixture for the treatment of psoriasis. United States patent US 4,943,432.

30. Even-Paz Z, Shani J (1989) The Dead Sea and psoriasis: historical and geographic background. International journal of dermatology 28(1): $1-9$

31. Maccardle RC, Engman MF (1941) XCIII. Spectrographic Analysis of Neurodermatitic Lesions: A HUMAN Magnesium Deficiency. Archives of Dermatology and Syphilology 44(3): 429-440.

32. Mikula C (2003) Balneo-phototherapy: a new holistic approach to treating psoriasis. Journal of the American Association of Nurse Practitioners 15(6): 253-259.

33. Paolisso G, Scheen A, D’Onofrio F, Lefebvre P (1990) Magnesium and glucose homeostasis. Diabetologia 33(9): 511-514.

$\begin{array}{ll}\text { BIOMEDICAL } & \text { Assets of Publishing with us } \\ \text { RESEARCHES } & \text { - Global archiving of articles } \\ \text { - Immediate, unrestricted online access } & \text { - Rigorous Peer Review Process } \\ & \text { - Authors Retain Copyrights } \\ & \end{array}$

